\title{
Herbal Cosmetics and Cosmeceuticals: An Overview
}

\section{Laxmi S Joshi ${ }^{1}$ and Harshal A Pawar ${ }^{2 \star}$}

${ }^{1}$ Research Scholar, Dr. L.H. Hiranandani College of Pharmacy, Ulhasnagar-3, Maharashtra, India

${ }^{2}$ Assistant Professor and Head of Department (Quality Assurance), Dr. L.H. Hiranandani College of Pharmacy, Ulhasnagar-3, Maharashtra, India

\begin{abstract}
Herbal cosmetics are formulated, using different cosmetic ingredients to form the base in which one or more herbal ingredients are used to cure various skin ailments. The name itself suggests that herbal cosmetics are natural and free from all the harmful synthetic chemicals which otherwise may prove to be toxic to the skin. Compared to other beauty products, natural cosmetics are safe to use. Cosmeceuticals are cosmetic-pharmaceutical hybrid products intended to improve the health and beauty of the skin by providing a specific result, ranging from acne-control and anti-wrinkle effects, to sun protection. Cosmeceuticals have medicinal benefits which affect the biological functioning of skin depending upon type of functional ingredients they contain. These are cosmetic products that are not just used for beautification but for different skin ailments. These products improve the functioning/texture of the skin by boosting collagen growth by eradicating harmful effects of free radicals, maintains keratin structure in good condition and making the skin healthier. There are numerous herbs available naturally having different uses in cosmetic preparations for skincare, hair care and as antioxidants. The current review highlights importance of herbal cosmetics, the herbs used in them and their advantages over the synthetic counterparts.
\end{abstract}

Keywords: Cosmetic; Cosmeceutical; Antioxidant; Drug; Herbs

\section{Introduction}

The concept of beauty and cosmetics dates back to ancient mankind and civilization. Generally herbal cosmetics are also referred to as natural cosmetics. Herbal cosmetics are formulated, using different cosmetic ingredients to form the base in which one or more herbal ingredients are used to cure various skin ailments. Plants are highly used for development of new drug products for cosmeceuticals and pharmaceutical applications [1]. Herbal cosmetics are the products in which herbs are used in crude or extract form [2].

Herbal Cosmetics, referred as Products, are formulated, using various permissible cosmetic ingredients to form the base in which one or more herbal ingredients are used to provide defined cosmetic benefits only, shall be called as "Herbal Cosmetics". Herbs do not produce instant cures. They offer a way to put the body in proper tune with nature [3]. A huge number of cosmetic and toiletry formulations have been designed and developed based u p o n Indian Herbs recently. Other than traditionally documented applications, some modern trials have also been using the utility of Indian herbs in Personal Care products. The demand of herbal medicines is increasing rapidly due to their skin friendliness and lack of side effects. The best thing of the herbal cosmetics is that it is purely made by the herbs and shrubs and thus is side-effects free. The natural content in the herbs does not have any side effects on the human body; instead provide the body with nutrients and other useful minerals [4]. The term Cosmeceuticals was first used by Raymond Reed founding member of U.S Society of Cosmetics Chemist in 1961. He actually used the word to brief the active and science based cosmetics. The above term was further used by Dr Albert Kligman in the year 1984 to refer the substances that have both cosmetic and therapeutic benefits [5]. Cosmeceuticals are cosmetic-pharmaceutical hybrids intended to enhance health and beauty through ingredients that influence the skin's biological texture and function [6].

\section{Advantages of Herbal Cosmetics over Synthetic [7]}

Herbal cosmetics are the modern trend in the field of beauty and fashion. These agents are gaining popularity as nowadays most women prefer natural products over chemicals for their personal care to enhance their beauty as these products supply the body with nutrients and enhance health and provide satisfaction as these are free from synthetic chemicals and have relatively less side-effects compared to the synthetic cosmetics.

Following are some of the advantages of using natural cosmetics which make them a better choice over the synthetic ones:

\section{Natural products}

The name itself suggests that herbal cosmetics are natural and free from all the harmful synthetic chemicals which otherwise may prove to be toxic to the skin. Instead of traditional synthetic products different plant parts and plant extracts are used in these products, e.g. aloe-vera gel and coconut oil. They also consist of natural nutrients like Vitamin E that keeps skin healthy, glowing and beautiful. For example, Aloevera is a herbal plant species belonging to liliaceae family and is naturally and easily available [8]. There are a rising number of consumers concerned about ingredients such as synthetic chemicals, mineral oils who demand more natural products with traceable and more natural ingredients, free from harmful chemicals and with an emphasis on the properties of botanicals [9].

\section{Safe to use}

Compared to other beauty products, natural cosmetics are safe to use. They are hypo-allergenic and tested and proven by dermatologists to be safe to use anytime, anywhere. Since they are made of natural ingredients, people don't have to worry about getting skin rashes or experience skin itchiness. Example - BHA (Butylated Hydroxyanisole) and BHT (Butylated Hydroxytoluene) are closely related synthetic antioxidants and are used as preservatives in lipsticks and moisturizers [10]. BHA and BHT can induce allergic reactions in the skin [11]. The international Agency for Research on Cancer classifies BHA as

*Corresponding author: Harshal A Pawar, Dr. L.H. Hiranandani College of Pharmacy, Ulhasnagar-3, Maharashtra, India, Tel: 918097148638; E-mail: harshal.dlhhcop@gmail.com

Received January 24, 2015; Accepted February 14, 2015; Published February 16 2015

Citation: Joshi LS, Pawar HA (2015) Herbal Cosmetics and Cosmeceuticals: An Overview. Nat Prod Chem Res 3: 170. doi:10.4172/2329-6836.1000170

Copyright: ( 2015 Joshi LS, et al. This is an open-access article distributed under the terms of the Creative Commons Attribution License, which permits unrestricted use, distribution, and reproduction in any medium, provided the original author and source are credited. 
a possible human carcinogen [12]. Herbal cosmetics contain natural antioxidants like vitamin C [13].

\section{Compatible with all skin types}

Natural cosmetics are suiTable for all skin types. No matter if you are dark or fair, you will find natural cosmetics like foundation, eye shadow, and lipstick which are appropriate irrespective of your skin tone. Women with oily or sensitive skin can also use them and never have to worry about degrading their skin condition. Coal tar-derived colors are used extensively in cosmetics, Coal tar is recognized as a human carcinogen and the main concern with individual coal tar a color (whether produced from coal tar or synthetically) is they can cause cancer [14]. But natural colors that are obtained from herbs are safer.

\section{Wide selection to choose from}

Natural cosmetics may still be a new type in the beauty industry but they already offer a variety of beauty products for all make up crazy people out there to choose from. One will find a variety of foundation, eye shadow, lipstick, blush, mascara, concealer and many more which are all naturally formulated. Furthermore, one will find locally made natural cosmetics or those made by famous designers worldwide. There exist a large variety of herbal extracts, to name a few Andrographis Paniculata (Kalmegh), Asparagus Racemosus (Shatawari), Boswellia Serrata (Salai Guggal), Asphalt (Shilajit) etc [15].

\section{Fits your budget}

Natural cosmetics are not that expensive. In fact, some of these products are more affordable than synthetic ones. They are offered at discounted prices and are sold for a cheap price during sales. Just need to survey enough to look for great deals. An estimate of WHO demonstrates about $80 \%$ of world population depends on natural products for their health care, because of side effects inflicted and rising cost of modern medicine. World Health Organization currently recommends and encourages traditional herbal cures in natural health care programs as these drugs are easily available at low cost and are comparatively safe [16].

\section{Not tested on animals}

Some cosmetics are initially tested on animals to ensure that they are safe and effective to use for human. However, natural cosmetics need not be tested on animals. These natural formulations are tested by experts in laboratories using state of the art equipment with no animals involved [7].

\section{No side effects}

The synthetic beauty products can irritate your skin, and cause pimples. They might block your pores and make your skin dry or oily. With natural cosmetics, one need not worry about these. The natural ingredients used assure no side effects; one can apply them anytime, anywhere. For example herbal cosmetics are free from parabens that are the most widely used preservative in cosmetics and can penetrate the skin [17]. And are suspected of interfering with hormone function (endocrine disruption) [10].

\section{Cosmeceuticals}

'Cosmeceuticals' is fastest growing segment of the beauty industry. Cosmeceuticals are cosmetic-pharmaceutical products intended to improve the health and beauty of the skin by providing a specific result, ranging from acne-control and anti-wrinkle effects, to sun protection. The concept discovered by Dr. Albert klingman states that 'The Cosmeceuticals are topical agents that are distributed across broad spectrum of materials, lying somewhere between pure cosmetics (lipstick and rouge) and pure drug (antibiotics, corticosteroids) [4].

\section{Regulatory status of cosmeceuticals}

Cosmeceuticals - cosmetics or drugs?

The legal difference between a cosmetic and a drug is determined by a product's intended use. Under present concept, the boundary at which a cosmetic product becomes drug is not well-defined and different laws and regulations apply to each type of product.

The drugs and cosmetic Act 1940 defines a drug and a cosmetic as; Drug-“ All medicines for internal or external use of human beings or animals and all substances intended to be used for ; or in the diagnosis, treatment, mitigation or prevention of any disease or disorder in humans or animals"[18]. Cosmetic-"Any article intended to be rubbed, poured, sprinkled or sprayed on or introduced into or applied to any part of the human body for cleansing, beautifying, promoting attractiveness or altering the appearance and includes any article intended for use as a component of cosmetic" [19].

Cosmetic and drug: Some products meet the definitions of both cosmetics and drugs. This may happen when a product has more than one intended uses. For example, a shampoo is a cosmetic because its intended use is to clean the hair. An antidandruff shampoo is a drug because its intended use is to treat dandruff. Among the cosmetic/drug combinations are toothpastes that contain fluoride, deodorants that are antiperspirants and moisturizers with sun-protection claims [20]. The claims made about drugs are subject to detailed analysis by the Food and Drug Administration (FDA) review and approval process, but cosmetics are not subject to mandatory FDA review. Although there is no legal category called cosmeceuticals, the term has found application to designate the products at the borderline between cosmetics and pharmaceuticals $[21,22]$.

Federal Food, Drug and Cosmetic Act do not recognize the term itself. It is also often difficult for consumers to determine whether 'claims' about the actions or efficiency of cosmeceuticals are valid unless the product has been approved by the FDA or equivalent agency. Some countries have the classes of products that fall between the two categories of cosmetics and drugs: for example, Japan has 'Quasi-drugs'; Thailand has 'controlled cosmetics' and Hong Kong has 'cosmetic-type drugs'. The regulations of cosmeceuticals have not been harmonized between the USA, European, Asian and other countries [23].

\section{Herbs Used in Cosmetics/Cosmeceuticals}

There are numerous herbs available naturally having different uses in cosmetic preparations for skincare, hair care and as antioxidants, fragrant etc. Some of the important examples are as follows:

\section{Skincare}

Coconut oil: It is produced by crushing copra, the dried kernel, which contains about $60-65 \%$ of the oil. Coconut oil contains a high amount of glycerides of lower chain fatty acids. Coconut oil is derived from the fruit or seed of the coconut palm tree Cocos nucifera, family Arecaceae. The melting point of coconut oil is 24 to $25^{\circ} \mathrm{C}$ $\left(75-76^{\circ} \mathrm{F}\right)$ and thus can be used easily in liquid or solid forms and is often used in cooking and baking. Coconut oil is excellent as a skin moisturizer and softener [4] (Figure 1).

Sunflower oil: It is the non-volatile oil extracted from sunflower seeds obtained from Helianthus annuus, family Asteraceae. Sunflower oil contains lecithin, tocopherols, carotenoids and waxes. It has 
Citation: Joshi LS, Pawar HA (2015) Herbal Cosmetics and Cosmeceuticals: An Overview. Nat Prod Chem Res 3: 170. doi:10.4172/23296836.1000170

smoothing properties and is considered non-comedogenic [4]. A simple yet cost-effective oil, well tried and tested for generations in a wide variety of emulsions formulated for face and body Products [24] (Figure 2).

Jojoba oil: It is a mixture of long chain, linear liquid wax esters extracted from the seeds of the desert shrub simmondsia chinenesis, family simmondsiaceae. Jojoba oil is easily refined to remove any odor, color it is oxidatively stable, and is often used in cosmetics as a moisturizer and as a carrier oil for exotic fragrances. Human sebum and jojoba oil are virtually identical. Sebum protects and moisturizes the skin and hair but is stripped away by chemicals, pollutants, sun and the aging process, resulting in dry skin and hair. Jojoba oil replenishes what skin and hair lose and restores them to their natural $\mathrm{pH}$ balance [25] (Figure 3).

Olive oil: This oil is a fixed oil extracted from the fruits of olea europaea, family oleaceae. The major constituents are triolein, tripalmitin, trilinolein, tristearate, monosterate, triarachidin, squalene, $\beta$-sitosterol and tocopherol. It is used as skin and hair conditioner in cosmetics like lotions, shampoos etc. It is a potent fatty acid penetration enhancer [25] (Figure 4)

Aloevera: Aloevera is a herbal plant species belonging to liliaceae family that is found only in cultivation, having no naturally occurring populations, although closely related aloes do have presence in northern Africa [8]. It is an ingredient in many cosmetics because it heals, moisturizes, and softens skin. Simply cut one of the aloe vera leaves to extract the soothing gel [4]. Aloe vera contains amino acids like leucine, isoleucine, saponin glycosides that provide cleansing action, vitamins A,C,E,B, choline, B12 and folic acid and provide antioxidant activity [26] (Figure 5).

\section{Antiaging}

Rhodiola rosea-Rhodiola rosea: It is commonly known as golden root, roseroot, Aaron's rod, arctic root, king's crown, lignum rhodium, orpin rose. It is a plant in the Crassulaceae family that habitats in cold regions of the world. It grows mainly in dry sandy ground at high altitudes in the arctic areas of Europe and Asia, Traditional folk medicine used $R$. rosea to increase physical endurance, work productivity, longevity, resistance to high altitude sickness, and to treat fatigue, depression, anemia, impotence, gastrointestinal ailments, infections, and nervous system disorders [27]. $R$. rosea is rich in phenolic compounds, known to have strong antioxidant properties [28] (Figure 6).

Carrot: It is obtained from the plant Daucus carota belonging to family Apiaceae. It is a valuable herb since ages as due to its richness in Vitamin A along with other essential vitamins. Carrot seed oil is used as anti-aging, revitalizing and rejuvenating agent [4]. The carrot gets its characteristic and bright orange colour from $\beta$-carotene, and lesser amounts of $\alpha$-carotene and $\gamma$-carotene. $\alpha$ and $\beta$-carotenes are partly metabolized into vitamin A in humans [29] (Figure 7).

Gingko: In China and Japan, the leaves and nuts of the Ginkgo biloba ( $G$. biloba) tree have been used for thousands of years to treat various medical conditions, including poor blood circulation; hypertension; poor memory, and depression, particularly among the elderly; male impotence. In addition, it is gaining a similar reputation as an antioxidant and anti-inflammatory agent. Ginkgo biloba belongs to family Ginkgoaceae, which grows to a huge size [30]. The G. biloba extract EGb 761, prepared from the tree's leaves, is a natural mixture containing flavone glycosides (33\%), mostly quercetin and kaempferol derivatives, and terpenes $(6 \%)$, which has exhibited the capacity to

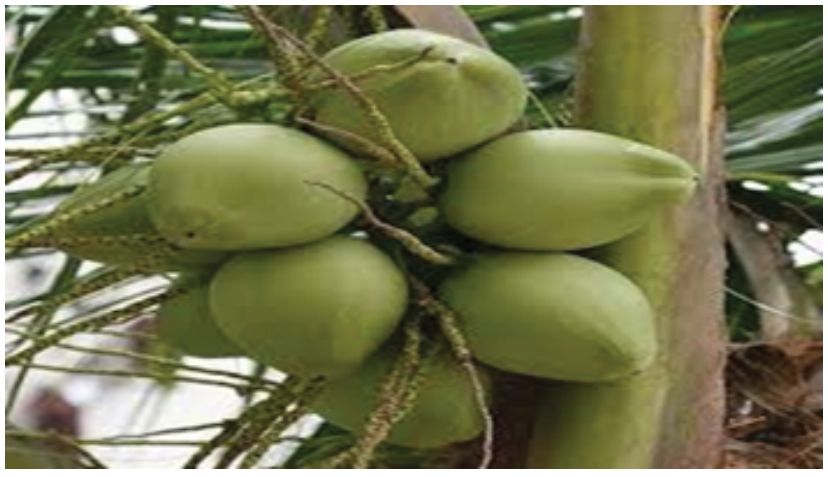

Figure 1: Coconut fruit/seed.

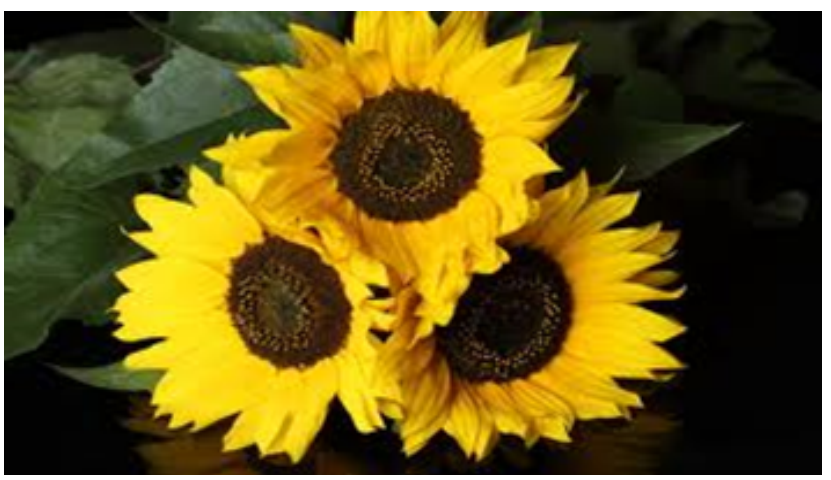

Figure 2: Sunflower.

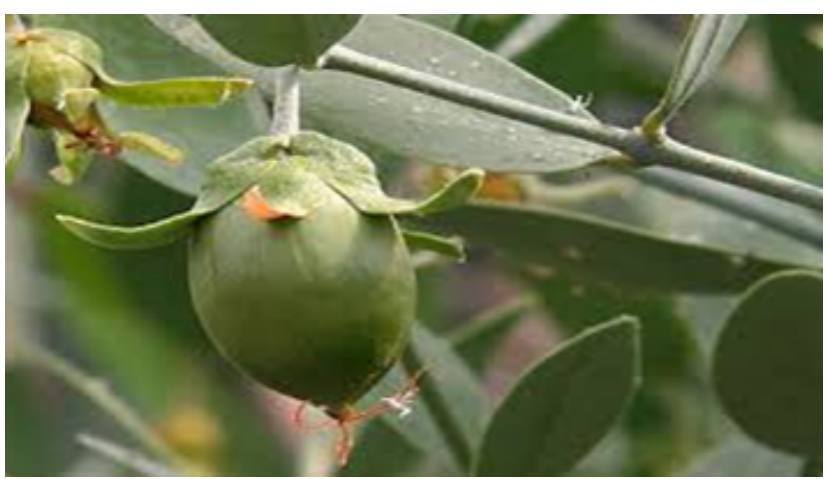

Figure 3: Jojoba fruit.

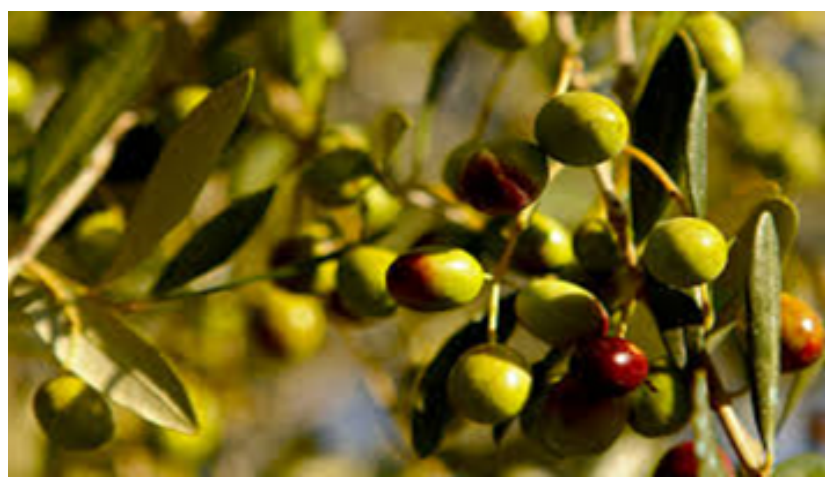

Figure 4: Olive fruit. 
Citation: Joshi LS, Pawar HA (2015) Herbal Cosmetics and Cosmeceuticals: An Overview. Nat Prod Chem Res 3: 170. doi:10.4172/23296836.1000170

Page 4 of 8

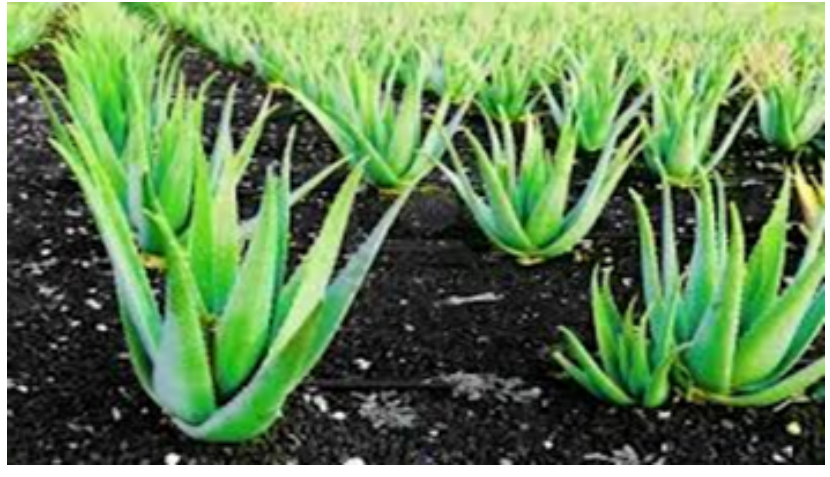

Figure 5: Aloe Vera.

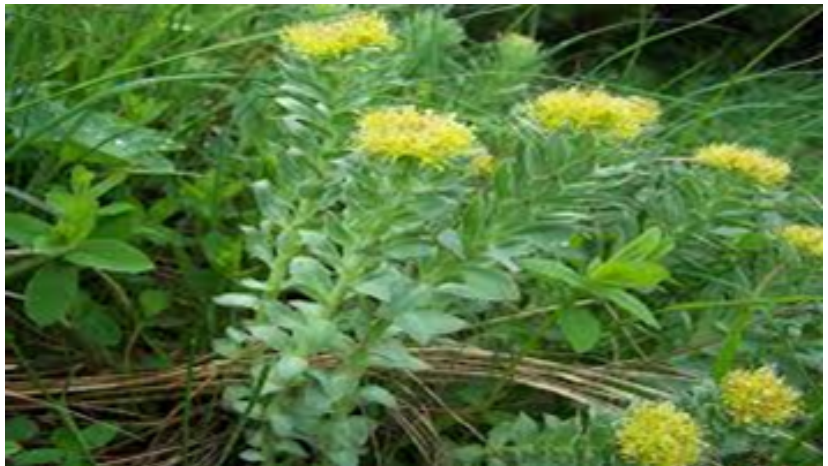

Figure 6: Rhodiola rosea.

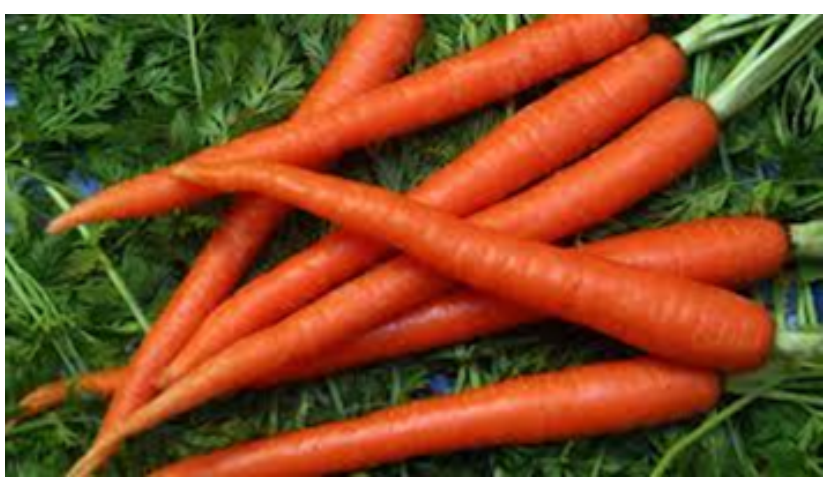

Figure 7: Carrots.

reduce the number of ultraviolet $B$ (UVB)-induced sunburn cells in mice [31] (Figure 8).

\section{Dandruff treatment}

Ayurveda has numerous natural medications wherein the most common herbs include Neem, Kapoor (naphthalene), and Henna, Hirda, Behada, and Amalaki, Magic nut, Bringaraj, Rosary Pea, Sweet Flag, Cashmere tree and Mandor [4].

Henna: Henna comes from the plant Lawsonia inermis family Lythraceae, which contain a dye molecule called Lawsone, which when processed produces Henna powder. Besides lawsone other constituents present are gallic acid, glucose, mannitol, fats, resin (2\%), mucilage and traces of an alkaloid. Leaves yield hennatannic acid and an olive oil green resin, soluble in ether and alcohol [32]. Lawsone isolated from the leaves of L.inermis has shown significant antifungal antibiotic effect [33] (Figure 9).

Neem: Neem or Margosa is a botanical relative of mahogany. It belongs to the family Meliaceae. The Latinized name of NeemAzadirachta indica-is derived from the Persian.

Azad=Free, dirakht $=$ Tree, $\mathrm{i}-$ Hind $=$ of Indian Origin.

The common treatment for the dandruff is Neem as it produces antifungal, antibacterial, pain-relieving, and anti- compounds that would treat dandruff [34] (Figure 10).

\section{Skin Protection}

Green tea: The tea plant (Camellia sinensis) has been cultivated in Asia for thousands of years [35]. The 4 major polyphenolic catechins present in green tea leaves are (2)-epicatechin (EC), EGC, (2)-EC-3-gallate, and EGCG, which is the most abundant $[36,37]$. It was found that green tea extracts or an individual green tea polyphenol (GTPP), especially epigallocatechin (EGC)-3-gallate (EGCG), inhibited two-stage chemical carcinogenesis (eg, induced by 7,12-di-methylbenz(a)anthracene [DMBA] and 12-O-tetradecanoylphorbol 13-acetate [TPA]), and photocarcinogenesis (induced by UVB) [38] (Figure 11).

Calendula: Calendula officinalis is reported to have a remarkable antioxidant activity, anti- inflammatory activity and wound healing activity [39]. A previous study demonstrated that the essential oil of Calendula consists mainly of $\alpha$-thujene, $\alpha$-pinene, 1,8-Cineole, dihydrotagetone and T-muurolol [40] (Figure 12).

Turmeric: It is a deep yellow-to-orange powder that comes

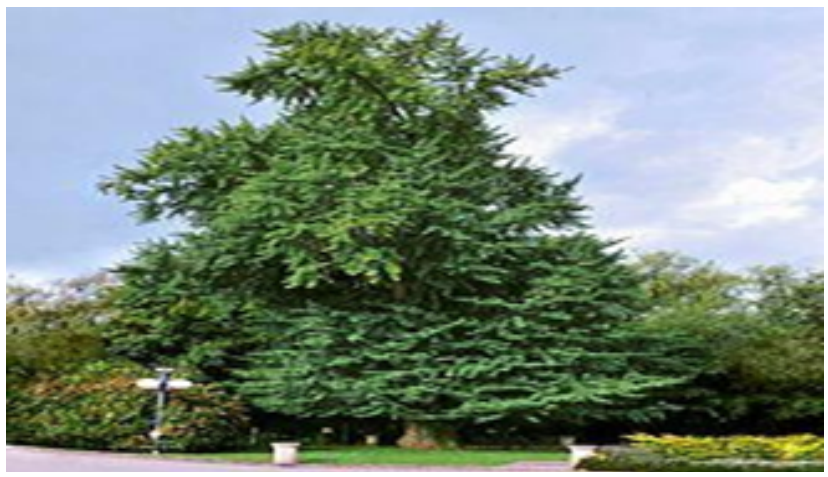

Figure 8: Gingko

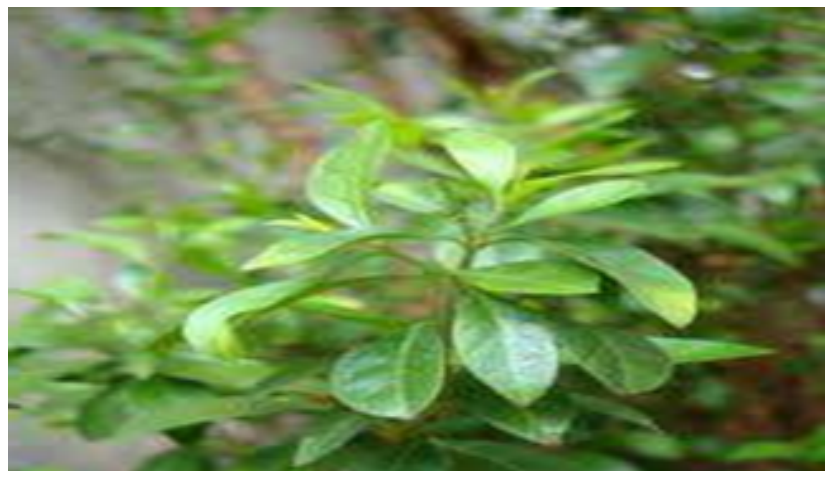

Figure 9: Henna leaves. 
Citation: Joshi LS, Pawar HA (2015) Herbal Cosmetics and Cosmeceuticals: An Overview. Nat Prod Chem Res 3: 170. doi:10.4172/23296836.1000170

Page 5 of 8

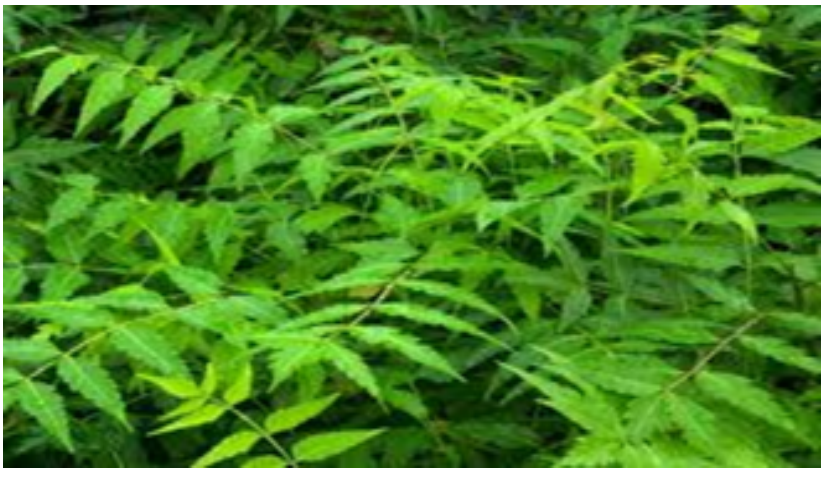

Figure 10: Neem leaves.

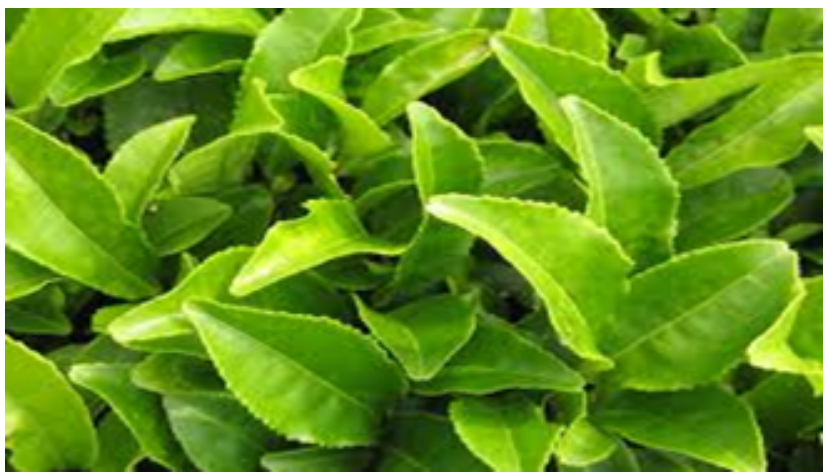

Figure 11: Green Tea.

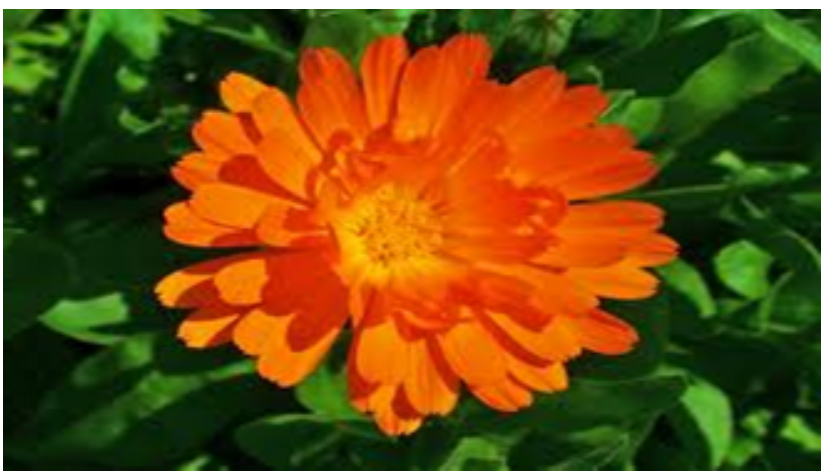

Figure 12: Calendula.

from the underground stems of the tropical perennial herb Curcuma longa of the family Zingiberaceae [41]. Turmeric contains a wide range of phytochemicals including, demethoxycurcumin, bisdemethoxycurcumin, zingiberene, curcumol, curcumenol, eugenol, tetrahydrocurcumin, triethylcurcumin, curcumin, turmerin, turmerones, and turmeronols. Curcumin is the phytochemical that gives a yellow color to turmeric and is now recognized as being responsible for most of the therapeutic effects [42]. Uses of turmeric include antiseptic, analgesic, anti-inflammatory, antioxidant, antimalarial, insect- repellant, and other activities associated to turmeric [43-46] (Figure 13).

\section{Haircare}

Amla: Amla is the name given to the fruit of a small leafy tree (Emblica Officinalis), which grows throughout India and yields an edible fruit. It is highly praised both for its high vitamin $\mathrm{C}$ content and for the precious oil, which is extracted from its seeds and pulp and used as a treatment for hair and scalp problems. It is used in eye syndromes, hair loss, and children ailments etc [3] (Figure 14).

Shikakai: Acacia concinna Linn. (Leguminosae) is a medicinal plant that grows in tropical rainforests of southern Asia. The fruits of this plant are used for washing hair, for improving hair growth, as an expectorant, emetic, and purgative. The powder of Acacia Concinna Linn shows the presence of saponins, alkaloid, sugar, tannin, flavanoids, anthraquinone glycosides [47] (Figure 15).

\section{Essential oils}

Rose oil: Roses are widely referred to as the world's favorite flower in part due to their vast diversity in plant habitat and floral

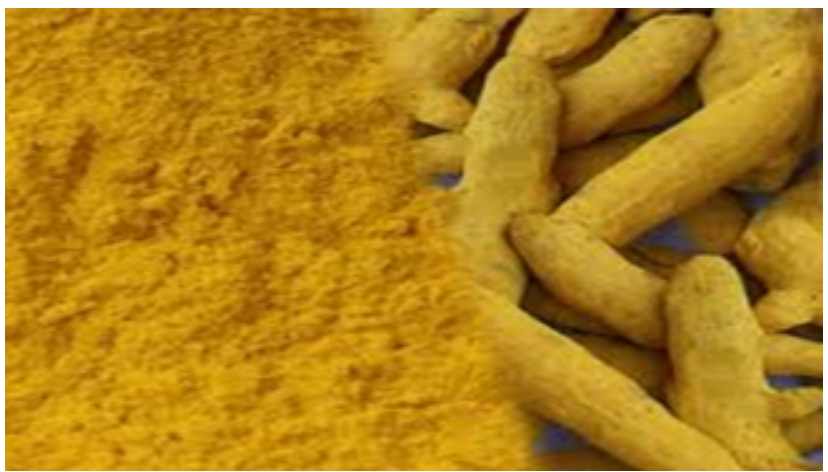

Figure 13: Turmeric rhizomes

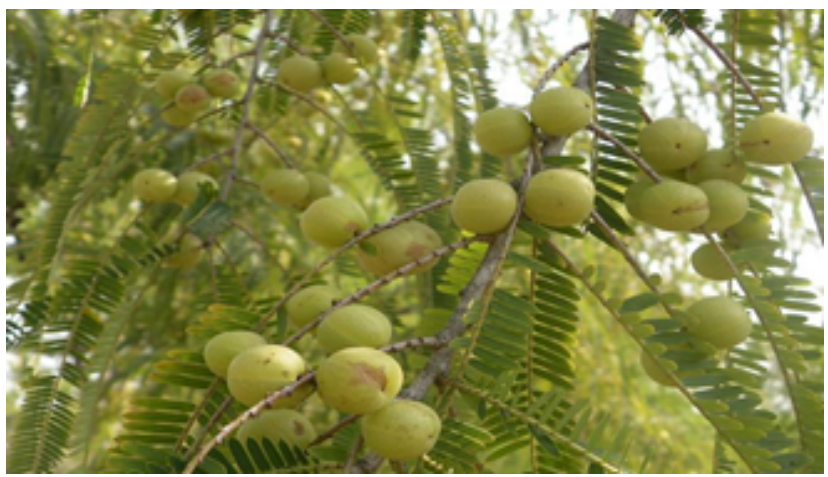

Figure 14: Amla fruit.

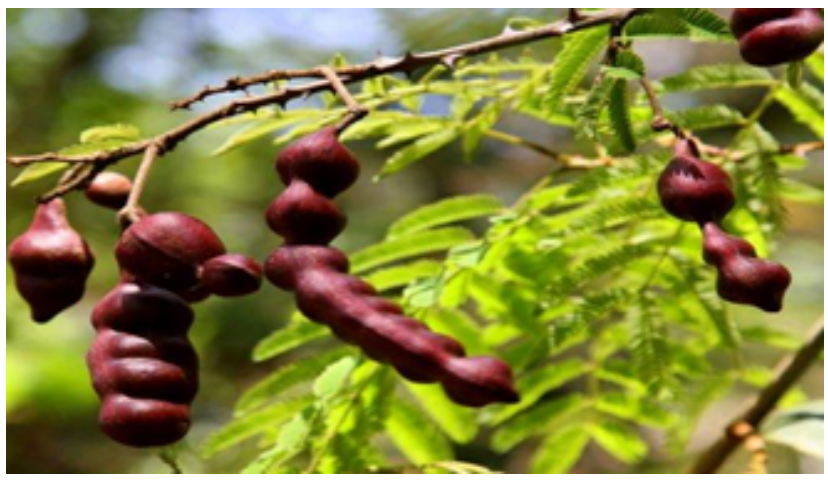

Figure 15: Shikakai fruits. 
Citation: Joshi LS, Pawar HA (2015) Herbal Cosmetics and Cosmeceuticals: An Overview. Nat Prod Chem Res 3: 170. doi:10.4172/23296836.1000170

characteristics. There are mainly four species of roses for oil production. These are Rosa damascena Mill., R. gallica L., R. moschata Herrm. and $R$. centifolia L. Rose oil and rose water have many therapeutic effects. Rose oil helps soothe the mind and heals depression, grief, nervous stress and tension. It also helps to heal wound and skin health [48] (Figure 16).

Eucalyptus oil: There are around 700 different species of Eucalyptus in the world, of which at least 500 produce a type of essential oil. It is produced by steam distillation from the leaves of Eucalyptus species (E. cinerea F. Muell., E. baueriana F. Muell., E. smithii R. T. Baker, E. bridgesiana R. T. Baker, E. microtheca F. Muell., E. foecunda Schau., E. pulverulenta Sims, E. propinqua Deane and Maiden, E. erythrocorys $F$. Muell.) etc. They are widely used in the preparation of liniments, inhalants, cough syrups, ointments, toothpaste and also as pharmaceutical flavors. The European Pharmacopoeia monograph for Eucalyptus oil sports a chromatographic profile: 1,8-cineole (eucalyptol; not less than70\%), limonene (4-12\%), a-pinene (2-8\%), $\alpha$ - phellandrene (less than 1.5\%), $\beta$-pinene (less than $0.5 \%$ ), camphor (less than 0.1\%) [49] (Figure 17).

\section{Antioxidants}

Tamarind: Tamarind or Tamarindus indica L. of the Fabaceae, subfamily Caesalpinioideae consists of amino acids, fatty acids and minerals of tamarind plant parts. The most distinguished characteristic of tamarind is its sweet acidic taste due to tartaric acid. Besides being a rich source of sugars, tamarind fruit is also an excellent source of vitamin $B$ and contain minerals, exhibit high antioxidant capacity that appear to be associated with a high phenolic content, and thus can be an important food source [51-55] (Figure 18).

Vitamin C: Vitamin C is necessary for the hydroxylation of proline, procollagen, and lysine. Vitamin $\mathrm{C}$ improves the changes caused by photo damage. Vitamin $\mathrm{C}$ has been used effectively to stimulate collagen repair, thus removing some of the effects of photo-aging on skin [13].

Vitamin E: (Alpha-tocopherol) is the major lipophilic antioxidant in plasma membranes and tissues. The term vitamin E collectively refers to 30 naturally occurring molecules (4 tocopherols and 4 tocotrienols), all of which exhibit vitamin E activity. Its major role is generally considered to be the arrest of chain propagation and lipid peroxidationby scavenging lipid peroxyl radicals, hence protecting the cell membrane from destruction [13].

\section{Marketed Preparations}

The marketed preparations are as follows (Table 1)

\section{Patented Products}

Below mentioned are the Patented Products (Table 2)

\section{Conclusion}

Herbal cosmetics are prepared, using permissible cosmetic ingredients to form the base in which one or more herbal ingredients are used to treat different skin ailments and for the beautification. The chemical formulation of all these cosmetic products includes addition of various natural additives like waxes, oils natural color, natural fragrances and parts of plants like leaves, etc. The Cosmeceuticals are agents that lie somewhere between pure cosmetics (lipstick and rouge) and pure drug (antibiotics, corticosteroids) methods. The cosmetic products are the best option to reduce skin problems such as hyper pigmentation, skin wrinkling, skin aging and rough skin texture etc. The demand of herbal cosmetic is rapidly expanding. The advantages

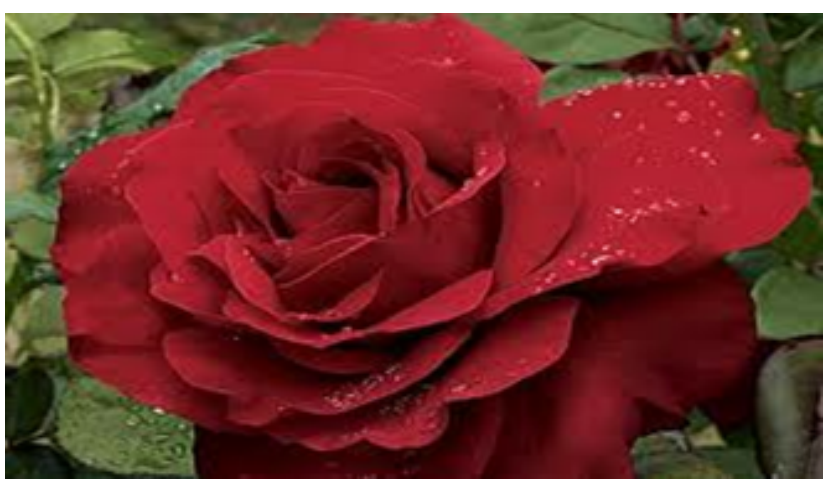

Figure 16: Rose flower.

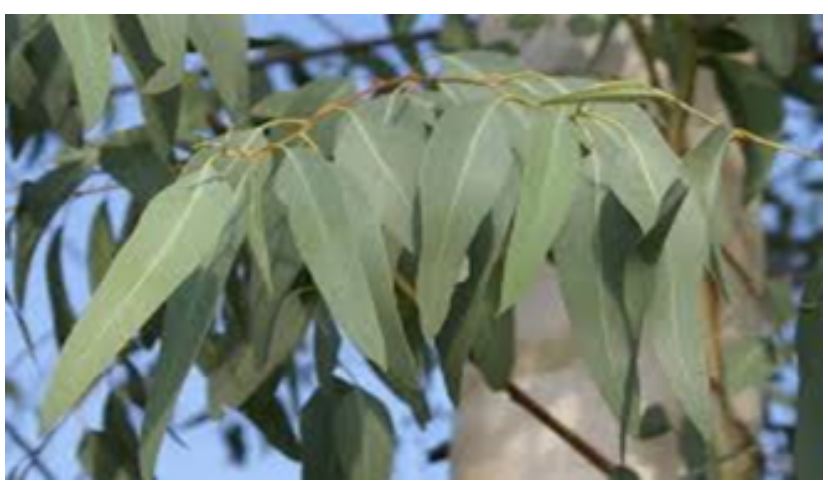

Figure 17: Eucalyptus leaves.

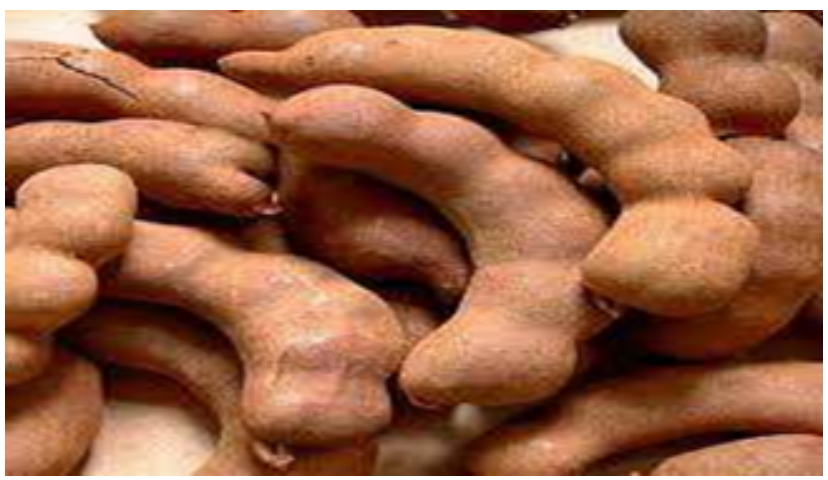

Figure 18: Tamarind.

\begin{tabular}{|c|c|c|}
\hline Product & Brand name & Company \\
\hline Face Wash & Deep Cleansing Apricot Face Wash & Himalaya herbals \\
\hline Shampoo & Anti-Dandruff Shampoo-Volume \& Bounce & Himalaya herbals \\
\hline Hair oil & Amla Brahmi hair oil & Ayur Herbals \\
\hline Cream & Herbal massage cream & Ayur Herbals \\
\hline $\begin{array}{l}\text { Anti Ageing } \\
\text { cream }\end{array}$ & Dabur Uveda Age Renew 5 cream & Dabur \\
\hline
\end{tabular}

Table 1: Marketed Preparations. 
Citation: Joshi LS, Pawar HA (2015) Herbal Cosmetics and Cosmeceuticals: An Overview. Nat Prod Chem Res 3: 170. doi:10.4172/23296836.1000170

Page 7 of 8

\begin{tabular}{|l|c|c|}
\hline Product & Patent number \\
\hline $\begin{array}{l}\text { Herbal cream (Aloe vera, Allium sativum, Gymnema syllvestra, Tridax procumbens, Gum } \\
\text { olibanum) }\end{array}$ & US6200570 B1 \\
\hline $\begin{array}{l}\text { Herbal preparation(Bacopa monnieri, Camellia sinensis, Curcuma longa, Silybum } \\
\text { marianum, Withania somnifera) }\end{array}$ & EP1825845 A1 \\
\hline $\begin{array}{l}\text { Herbal cosmetic compositions containing herbs in mixture of surfactants, essential oils } \\
\text { etc. Herbs are selected from camomile, rosemary, mint, sage, lavender, citron, bergamot, } \\
\text { juniper, rose, lime (linden), stinging nettle and witch-hazel. }\end{array}$ & DE4133085 A1 \\
\hline $\begin{array}{l}\text { Dry herbal, cleaning compositions ( Bassica malabarica, cocoa nucifera sapindus } \\
\text { trifoliatus, hibiscus rosa sinesis, trigonella foenum graeceum) }\end{array}$ & EP0908171 A1 \\
\hline $\begin{array}{l}\text { Cosmetic or dermatologic composition containing at least one saponine of the } \\
\text { ginsenoside type, and its applications particularly to hair care }\end{array}$ & WO1994006402 A2 \\
\hline
\end{tabular}

Table 2: Patented Products.

of herbal cosmetics are lower cost, side effects free, environmental friendly, safe to use etc. Also has a great future ahead as compared to the synthetic cosmetics. Proper regulation of these herbs and standardization will lead to tremendous and significant growth in herbal cosmetics field.

\section{References}

1. Joshi H (2012) Potentials of traditional medicinal chemistry in cosmetology industry; prospectives and perspectives. Anaplastology an open access journal 1: 3

2. Sahu AN, Jha S, Dubey SD (2011) Formulation \& Evaluation of curcuminoid based herbal face cream. Indo-Global Journal of Pharmaceutical Sciences 1 : $77-84$

3. Pandey S, Meshya N, Viral D (2010) Herbs play an important role in the field of cosmetics. International Journal of Pharm Tech Research 2: 632-639.

4. Gediya SK, Mistry RB, Patel UK, Blessy M, Jain HN (2011) Herbal plants : used as cosmetics. J Nat Prod Plant Resour 1: 24-32.

5. Saha R (2012) Cosmeceuticals and Herbal drugs: practical uses. International journal of pharmaceutical Research and Sciences 3: 59-65.

6. Sharma HD, Paramesh R (2010) Trends in aging and skin care: Ayurvedic concepts. Journal of Ayurveda and Integrative Medicine 1: 110-113.

7. Top 7 Advantages of using Natural Cosmetics.

8. Akinyele BO, Odiyi AC (2007) Comparative study of the vegetative morphology and the existing taxonomic status of Aloe vera. Journal of plant sciences 2 : 558-563.

9. Escamilla M, Ferre A, Hidalgo C, Fuentes N, Kaps R, et al.(2012) Revision of European Ecolabel Criteria for Soaps, Shampoos and Hair Conditioners. Joint Research Centre European Commission 1-40.

10. Suzuki D (2010) The "Dirty Dozen" Ingredients Investigated in the David Suzuki Foundation Survey of Chemicals in Cosmetics. Backgrounder 1-15.

11. Occupational Exposure to Hazardous Agents.

12. (1978) International Agency for Research on Cancer (IARC) Monographs on the Evaluation of Carcinogenic Risks to Humans 17: 1-365.

13. Kadam VS, Chintale AG, Deshmukh KP, Nalwad DN (2013) Cosmeceuticals an emerging concept: A comprehensive Review. International journal of research in pharmacy and chemistry 3: 308-316.

14. Winter RA (2009) Consumers Dictionary of Cosmetic Ingredients (7thedn.) Three Rivers press United states USA.

15. Ayurvedic \& Herbal Products.

16. Sharma A, Shanker C, Tyagi LK, Singh M, Rao ChV (2008) Herbal Medicine for Market Potential in India : An overview. Academic Journal of Plant Sciences 1: 26-36.

17. U.S. Food and Drug Administration, "Parabens".

18. Kuchekar BS (2008) Pharmaceutical jurisprudence. 5-17.

19. Jain NK (2007) A textbook of Forensic pharmacy (7thedn.) MK Jain Vallabh Prakashan, Delhi, India.

20. Ligade VS, Udupa N (2010) Pharmaceuticals, Cosmeceuticals and
Nutraceuticals: An Overview of Regulations (1stedn.) Career Publications.

21. Dureja H, Kaushik D, Gupta M, Kumar V, Lather V (2005) Cosmeceuticals: An Emerging Concept. Indian Journal of Pharmacology 37: 155-159.

22. Hammes C (1997) Cosmeceuticals: The cosmetic-drug borderline. In Drug discovery approaches for developing cosmeceuticals: Advanced Skincare Cosmetic Products. Hori H, Southborough.

23. Trueb RM (2001) The value of hair cosmetics and pharmaceuticals. Dermatology 202: 275-82.

24. Athar M, Syed MN (2005) Taxonomic perspective of plant species yielding vegeTable oils used in cosmetics and skin care products. African Journal of Biotechnology 4: 36-44.

25. Rabasco AAM, Gonzalez RML (2000) Lipids in pharmaceutical and cosmetic preparations. Grasas y Aceites 51: 74-96.

26. Basmatekar G, Jais N, Daud F (2011) Aloevera: A valuable multifunctional cosmetic ingredient. Int J Med Arom Plants 1: 338-341.

27. Brown RP, Gerbarg PL, Ramazanov Z (2002) Rhodiola rosea: A phytomedical overview. Herbal Gram. The Journal of the American Botanical Council 56: 40-52.

28. Furmanowa M, Skopinska RE, Rogala E, Malgorzata H(1998) Rhodiola rosea in vitro culture: phytochemical analysis and antioxidant action. Acta Societis Botanicorum Poloniae 67: 69-73

29. Strube M, Dragsted OL (1999) Naturally occuring Antitumourigens. IV Carotenoids except $\beta$-carotene.

30. Jain A, Dubey S, Gupta A, Kannojia P, Tomar V (2010) Potential of herbs as cosmeceuticals. IJRAP 1: 71-77.

31. Ozkur MK, Bozkurt MS, Balabanli B, Aricioglu A, Ilter N, et al. (2002) The effects of EGB 761 on lipid peroxide leaves and superoxide dismutase activity in sunburn. Photodermatol photoimmunol photomd 18: 117-120.

32. Chaudhary G, Goyal S, Poonia P (2010) Lawsonia inermis Linnaeus: A Phytopharmacological Review. International Journal of Pharmaceutical Sciences and Drug Research 2: 91-98.

33. Dixit SN, Srivastava HS, Tripathi RD (1980) Lawsone, The antifungal antibiotic from leaves of lawsonia inermis and some aspects of its mode of action. Indian phytopathol 31: 131-133.

34. Anand N, Aquicio JM, Anand A (2010) Antifungal properties of Neem (Azadirachta indica) leaves extract to treat Hair Dandruff. E-International Scientific Research Journal 2: 244-252.

35. Kuroda Y, Hara Y (1999) Antimutagenic and anticarcinogenic activity of tea polyphenols. Mutation Research/Reviews in Mutation 436: 69-97.

36. Adhami VM, Mukhtar H, Ahmad N, Farrukh A, Yukihiko H (1995) Tea polyphenols as cancer chemopreventive agents. T cell Biochem suppl 22: 169-180.

37. Katiyar SK, Elmets CA (2001) Green tea polyphenols skin protection and antioxidant (Review). Int J oncol 18: 1307-1313.

38. Mukhtar H, Katiyar SK, Agarwal R (1994) Green tea and skin anticarcinogenic effects. J invest Dermatol 102: 3-7.

39. Muley BP, Khadabadi SS, Banaase NB (2009) Phytochemical constituents and pharmacological activities of calendula officinalis Linn (Asteraceae): A review. Trop J pharma Res 8: 455-465.

40. Okoh OO, Sadimenko AP, Asekeen OT, Afolayan AJ (2008) The effects of 
Citation: Joshi LS, Pawar HA (2015) Herbal Cosmetics and Cosmeceuticals: An Overview. Nat Prod Chem Res 3: 170. doi:10.4172/23296836.1000170

Drying on the chemical components of Essential oils of Caledula officinalis $L$. African J Biotechnol 7: 1500-1502.

41. Damalas CA (2011) Potential uses of turmeric (curcuma longa) products as alternative means of pest management in crop production. Plant Omics Journal 4: $136-141$.

42. Aggarwal BB, Sundaram C, Malani N, Ichikawa H (2007) Curcumin: The Indian solid Gold. Adv Exp Med Biol 595: 1-75.

43. Fujiyama YF (1992) Effects of sesamin and curcumin on delta 5-desaturation and chain elongation of polyunsaturated fatty acid meabolism in primary cultured fatty acid metabolism in primary cultured rat hepatocytes. J Nutr sci vitaminol (Tokyo) 38: 353-363.

44. Chaudhari KR (1950) Turmeric, haldi or haridra, in eye diseases. Antiseptic 47: $67-68$.

45. Nadkarni KM, Nadkarni AK (1976) Curcuma longa in India materia. Popular Prakashan 414-418.

46. Saikia AP, Ryakala VK, Sharma P, Goswami P, Bora U (2006) Ethnobotany of medicinal plants used by Assamese people for various skin ailments and cosmetics. J Ethnopharmacol 149-157.

47. Khanpara K, Renuka V, Shukla J, Harsha CR (2012) A Detailed Investigation of shikakai (Acacia concinna Linn) fruit. Journal of Current Pharmaceutical Research 9: 06-10.
4. Haghighi M, Tehranifar A, Nikbakht A, Kafi M (2008) Research and curren profile of Iranian production of Damask Rose (Rosa Damascena Mill) International sociey of Horticulture Science 769: 449-455

49. Sefidkon F, Assareh MH, Abravesh Z, Barazandeh MM (2007) Chemica composition of the Essential oils of four cultivated Eucalyptus species in Iran as medicinal plants [E. microtheca, E. spatbulata, E. largiflorens and E. torquata]. Iranian Journal of Pharmaceutical Research 6: 135-140.

50. Caluwe ED, Halamova K, Damme PV (2010) Tamarindus indica L.-A review of traditional uses, phytochemistry and pharmacology. Journal Afrika Focus 23: $53-83$.

51. Rao Diwan PV (2001) Herbal formulation useful as therapeutic and cosmetic applications for the treatment of general skin disorders. US6200570 B1, March 13.

52. Marini JL (2007) Cosmetic herbal compositions. EP1825845 A1, August 29.

53. Mengoli $F(1993)$ Herbal cosmetic compsns-contg. Herbs in mixt of surfactants, essential oils, etc. DE4133085 A1, April 1.

54. Neelakantan K (1999) Dry herbal, cleaning compositions. EP0908171 A1, April 14.

55. Bonte F, Dumas M, Maybeck A (1994) Cosmetic or dermatologic composition containing at least one saponine of the ginsenoside type, and its applications particularly to hair care. WO1994006402 A2, March 31 